\title{
NUTRITIONAL STATUS AND EATING DISORDERS AMONG MEDICAL STUDENTS FROM THE CLUJ-NAPOCA UNIVERSITY CENTRE
}

\author{
MARIA IRINA BRUMBOIU' ${ }^{1}$, IRINA CAZACU ${ }^{2}$, GAUTIER ZUNQUIN ${ }^{3}$, \\ FLAVIA MANOLE ${ }^{4}$, CRISTINA IONELA MOGOSAN ${ }^{2}$, \\ ALESSANDRO PORROVECCHIO ${ }^{5}$, THIERRY PEZE ${ }^{3}$, \\ MARIE-PIERRE TAVOLACCI ${ }^{6}$, JOEL LADNER $^{6}$
}

\author{
${ }^{1}$ Epidemiology Department, Iuliu Hatieganu University of Medicine and \\ Pharmacy, Cluj-Napoca, Romania \\ ${ }^{2}$ Pharmacy Department, Iuliu Hatieganu University of Medicine and Pharmacy, \\ Cluj-Napoca, Romania \\ ${ }^{3}$ University of the Littoral Opal Coast - EA 7369 - URePSSS - Unité de Recherche \\ Pluridisciplinaire Sport Santé Société, F-59383 Dunkerque, France \\ ${ }^{4}$ Nutrition Department, Cluj-Napoca Unit - The Network of International \\ Francophone Clinical Epidemiology, Cluj-Napoca, Romania \\ ${ }^{5}$ University of Lille - EA 7369 - URePSSS - Unité de Recherche Pluridisciplinaire \\ Sport Santé Société, F-59000 Lille, France \\ ${ }^{6}$ Rouen University Hospital, Rouen, France; INSERM Unit 1073, School of \\ Medicine, University of Rouen, Rouen, France
}

\section{Abstract}

Background and aims. The nutritional disorders are modifiable predisposing factors of the current leading causes of morbidity and premature mortality, such as cardiovascular diseases, diabetes and cancers. An early recognition of appropriate interventions could decrease the burden of medical costs and increase the healthy life expectancy. The aims of our study were the description of nutritional status, its associated factors, and the detection of eating disorders among Romanian medical students of the "Iuliu Hatieganu" University of Medicine and Pharmacy, Cluj-Napoca.

Methods. A cross-sectional study was conducted during the 2015-2016 academic year, including medical students from all study years, by an online questionnaire. The statistics, both descriptive and inferential, were calculated using EpiInfo.

Results. A total of 222 students from the University Romanian section were included, with a sex-ratio (men:women) of 0.22. The average body mass index of the medical students included was $21.3 \pm 3.3 \mathrm{~kg} / \mathrm{m} 2$, for females it was $20.7 \pm 3 \mathrm{~kg} / \mathrm{m} 2$ and for males $23.9 \pm 3.1 \mathrm{~kg} / \mathrm{m} 2$. For the nutritional disorders such as overweight, the prevalence among males $(30 \%)$ had a net predominance $(p<0.001)$ over females $(4.4 \%)$, while for underweight, it was prevalent only for female students (20.3\%). Overweight was associated with low academic performance (odds ratio $(O R)=7.2 ; 95 \%$ confidence interval (95\% CI): 1-53.94), smoking (OR=2.4; 95\% CI: 1-5.76) and binge drinking $(O R=3 ; 95 \%$ CI: 1.26-7.25). Eating disorders were reported by $25.7 \%$ of the students and were significantly more prevalent in students in the second academic study cycle (47.4\%; 95\% CI: 34.7-60.3\%) and in students with jobs (7\%; 95\% CI: 2.3-16.1\%).

Conclusions. In this survey, two different distribution models of nutritional disorders for both genders were identified, with the predominance of overweight among men. Eating disorders were more prevalent among students in the second study cycle and those with jobs at the same time.

Keywords: nutritional status, eating disorders, medical students

Manuscript received: 12.03 .2018

Received in revised form: 13.06.2018

Accepted: 26.06.2018

Address for correspondence: irinabrumboiu@gmail.com 


\section{Background and aims}

Many recent studies showed that the nutritional status can alter the health and well-being of a person. Among nutritional disorders, overweight and obesity are linked to the most frequent diseases nowadays such as cardiovascular diseases, malignancies and diabetes $[1,2]$. This pattern of morbidity is common in developed countries and it is expanding to other countries too [3,4]. Modelling techniques predict a further great burden in adult pathology due to a decreasing trend in the age of the occurrence of severe cardiovascular events, especially for stroke [5-7]. As the disease onset is earlier in life, the chronic evolution and disabilities last longer, requiring more medical services, resources and supplies, which overload healthcare expenses. Reducing such consequences can be achieved through preventive measures. The selection of the appropriate preventive and control measures may be taken only by having extensive information about these disorders $[1,4]$.

For many years in Romania, cardiovascular diseases and cancers remained the leading causes of mortality. Cardiovascular diseases accounted for 58\%, and cancers for $20 \%$ of all deaths registered in 2014 (the most recent statistical year published) [8]. These diseases causing premature death entail low life expectancy, which was 75 years in 2015 (the last statistical year published). With this life expectancy in the range of 83.4 to 66.3 years, Romania was placed in the $35^{\text {th }}$ position out of 50 countries of the WHO European region [2]. These data suggest a low efficiency of preventive measures applied so far and a large exposure to risk factors. In order to establish the impact of preventive programs and the risk factors, specific epidemiological studies are needed. A correction of existing preventive programs would be possible after their evaluation. At the same time, new intervention programs on modifiable factors and also prioritization must be conducted on the basis of information about risk factors and particularities in our population.

Distinctly to the general population, students are the most vulnerable group to gain a disordered lifestyle and bad health habits [9]. For most students, this lifetime period is the most challenging because of sudden change of the geographical and social environment in the context of the need to make efforts for preparing for the future profession. Among all students' categories, the medical students are the most overloaded because of many exams, the amount of knowledge needed to be acquired for medical training and the high level of stress [10-12]. Having this particular group, with the aim to identify and evaluate its characteristics, we started asurvey in 2015 on lifestyle and behaviors of students in our university. The project is coordinated by University of Rouen, and conducted by a multidisciplinary team in collaboration with the University of Lille and University of the Littoral Opal Coast, France. This survey takes place in each academic year and will continue for the next ten years, having also a multiannual analysis. The study was granted with the approval of the University Ethics Committee.

In this paper we present the survey's first results describing the medical students' nutritional status, its associated factors and the eating disorders.

\section{Methods}

We conducted a cross-sectional survey during the academic year 2015-2016, in which, students were invited to fill an online anonymous questionnaire. The invitation was made in the same way by the entire working team during the teaching activities. After a brief presentation of the study, the link for the online questionnaire was provided to each responsible of the student's group and then disseminated to everyone through the information system used for the students' current organizational activities. Complementarily, the students posted the invitation on their website and blogs usually used by medical students.

Inclusion criteria was that the student was enrolled in the Romanian section of the Iuliu Hatieganu University of Medicine and Pharmacy, Cluj-Napoca, in any study year. For the analysis, only the full completed study forms were kept. The validation of the record of the data correctness was designed for each parameter through the structure of the online form. The final validation and the rejection of incomplete forms were done in Excel software.

The questionnaire included items regarding the anthropometric measures (weight, height), personal characteristics (age, gender, marital status, type of residency, job), the academic year and performance, the alcohol intake, smoking and practicing sports. For eating disorders screening, the SCOFF (Sick, Control, One stone, Fat, Food) free access self-reporting questionnaire was used [13].

The body mass index (BMI) and the SCOFF score were calculated by using the primary data. The academic year studies were divided into the first (study years 1 to 3 ) and second (study years 4 to 6) cycles. The descriptive statistical analysis for quantitative variable used the central tendency and dispersion (mean, standard deviation, range) and for qualitative data, the proportion and their confidence intervals, which were conducted in EpiInfo program. The $t$ test was used for the statistical significance of the differences between means and the $\mathrm{z}$ test for proportions. The association was tested through odds ratio (OR), confidence intervals (CI) and chi squared test for the statistical significance.

\section{Results}

In this survey, a total of 222 fully completed online questionnaires were acquired, representing a response rate of $21 \%$ from around 1,050 students invited to participate at the study. They originated differently $(p<0.001)$ from all six years of medical academic studies, the most represented being the second year, from which came $30.9 \%$ of the 
students (Figure 1). The sex ratio (0.22), males (number of subjects $(\mathrm{N})=40)$ to females $(\mathrm{N}=182)$ showed a 4.6 times women's predominance over men.

Regarding the basic parameters of nutritional status, the students were, on average, $60.9 \pm 12.7 \mathrm{~kg}$ body weight, $168.5 \pm 8.5 \mathrm{~cm}$ height and $21.3 \pm 3.3 \mathrm{~kg} / \mathrm{m}^{2}$ BMI (Table I). Female students had in average $57 \pm 8.8 \mathrm{~kg}, 165.8 \pm 5.8 \mathrm{~cm}$ height and $20.7 \pm 3 \mathrm{~kg} / \mathrm{m}^{2} \mathrm{BMI}$, while the male had $78.3 \pm 13.2$ $\mathrm{kg}$ body weight for a height of $180.7 \pm 7.9 \mathrm{~cm}$ and $23.9 \pm 3.1$ $\mathrm{kg} / \mathrm{m}^{2}$ BMI. The men's average age (22.3 years) was slightly, but significantly $(\mathrm{p}=0.005)$ higher than that of women $(21.4$ years). As physical activity, sport practicing was more prevalent $(\mathrm{p}<0.001)$ among males $(\mathrm{N}=23$ or $57.5 \%)$ than among females $(\mathrm{N}=64$ or $35.2 \%)$, but without significant differences in the amount of the sport they practiced.

Normal weight was recorded in $72.5 \%$ of students, with a difference close to statistical significance $(\mathrm{p}=0.077)$ between females (73.7\%) and males (67.5\%) (Figure 2 ). Overweight was found in $4.4 \%$ of female students, significantly $(p<0.001)$ lower than $30 \%$ of males who were overweight. The obese students corresponded to the first two obesity classes, without differences between genders. Underweight persons were found only among the female students $(20.3 \%), 2.2 \%$ of them reaching the moderate and
$0.5 \%$ the severe underweight subclass.

Among the analyzed factors, overweight (including obesity) was associated with the male gender $(\mathrm{OR}=5.9 ; 95 \%$ CI: 2.37-14.47; $\mathrm{p}=0.001$ ), a low academic performance by repeating at least one study year $(\mathrm{OR}=7.2 ; 95 \% \mathrm{CI}$ : 1-53.94; $\mathrm{p}=0.025)$, being smoker $(\mathrm{OR}=2.4 ; 95 \% \mathrm{CI}: 1-5.76$; $\mathrm{p}=0.045)$ and binge drinking $(\mathrm{OR}=3 ; 95 \% \mathrm{CI}: 1.26-7.25$; $\mathrm{p}=0.01$ ) (Table II). In contrast, underweight individuals were 7.5 times $(95 \% \mathrm{CI}: 1-56.7 ; \mathrm{p}=0.012)$ more frequent in females, less frequently overtaking alcohol through binge drinking $(\mathrm{OR}=0.2 ; 95 \% \mathrm{CI}$ : 0.06-0.65; $\mathrm{p}=0.003)$ and more rarely practicing sports $(\mathrm{OR}=0.3 ; 95 \% \mathrm{CI}: 0.13-0.77$; $\mathrm{p}=0.008$ ).

Through the SCOFF questionnaire 57 persons with eating disorders were observed, representing 25.7\% (95\% CI: $20.3-31.7 \%$ ) of all students. The two groups of students identified as SCOFF positive and negative were not significantly different in terms of parameters reflecting the nutritional status and the physical activities (Table III). The only statistical significant differences remained the mean BMI between genders $(p<0.001)$ in both SCOFF groups and the mean age $(\mathrm{p}=0.012)$ for men who were slightly older than women in the positive SCOFF group and not in the negative SCOFF one.

Table I. Indicators of the basic quantitative parameters of the nutritional status and the physical activity of students ( $\mathrm{N}=222$ : 182 female and 40 male).

\begin{tabular}{|l|l|l|l|l|l|l|}
\hline \multirow{2}{*}{ Parameters } & \multicolumn{3}{l|}{ Female } & \multicolumn{2}{l|}{ Male } & \multicolumn{2}{l|}{ The entire sample } \\
\cline { 2 - 8 } & mean $\pm \mathrm{SD}^{1}$ & range & mean $\pm \mathrm{SD}^{1}$ & range & mean $\pm \mathrm{SD}^{1}$ & range \\
\hline Weight $(\mathrm{kg})$ & $57 \pm 8.8$ & $36-100$ & $78.3 \pm 13.2$ & $57-114$ & $60.9 \pm 12.7$ & $36-114$ \\
\hline Height $(\mathrm{cm})$ & $165.8 \pm 5.8$ & $149-184$ & $180.7 \pm 7.9$ & $165-197$ & $168.5 \pm 8.5$ & $149-197$ \\
\hline BMI $\left(\mathrm{kg} / \mathrm{m}^{2}\right)$ & $20.7 \pm 3$ & $14.2-35.9$ & $23.9 \pm 3.1$ & $20-32$ & $21.3 \pm 3.3$ & $14.2-35.9$ \\
\hline Age (years) & $21.4 \pm 1.8$ & $18-28$ & $22.3 \pm 2.1$ & $19-27$ & $21.5 \pm 1.9$ & $18-28$ \\
\hline Sports (hours per week) & $3.8 \pm 1.5$ & $1-8$ & $4 \pm 2.3$ & $2-12$ & $3.9 \pm 1.8$ & $1-12$ \\
\hline Sports (months per year) & $9.1 \pm 3$ & $2-12$ & $10 \pm 2.9$ & $2-12$ & $9.3 \pm 3$ & $2-12$ \\
\hline
\end{tabular}

${ }^{1} \mathrm{SD}$ : standard deviation.

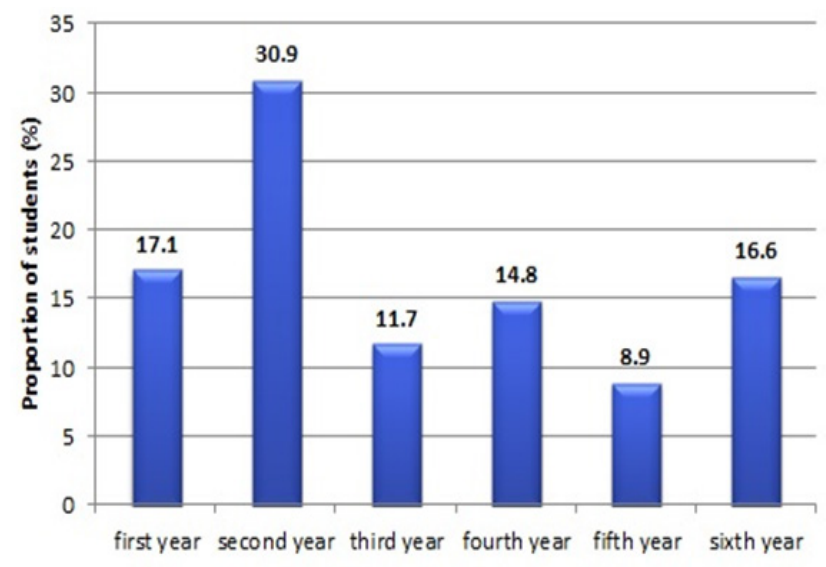

Figure 1. The distribution of students by the academic study year during the 2015-2016 study period $(\mathrm{N}=222)$.

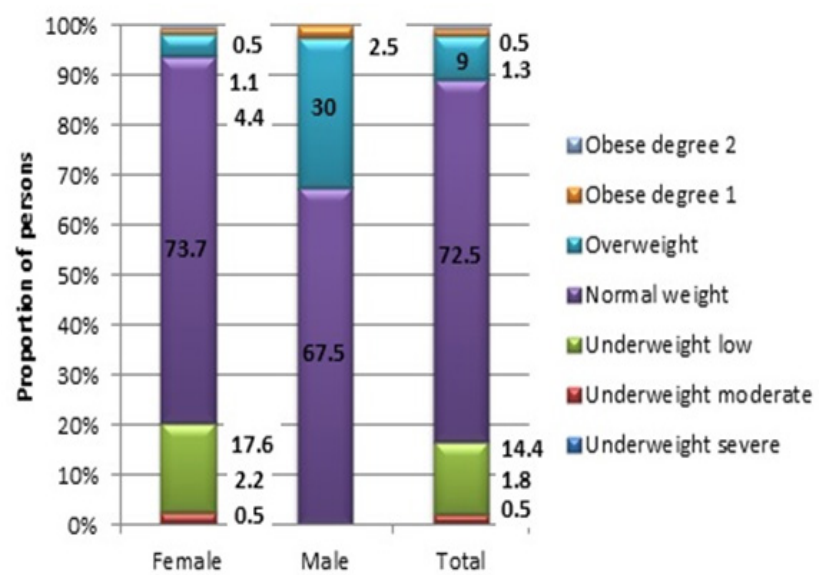

Figure 2. The categories of nutritional status stratified by the level of BMI, among students included in the sample study, in the 20152016 study period $(\mathrm{N}=222)$. 
Also, regarding the characteristics measured through qualitative parameters, the students alleged to have eating disorders by SCOFF positive compared to SCOFF negatives, were significantly more common persons with normal weight $(77.2 \% ; 95 \%$ CI: $65-86.7 \% ; \mathrm{p}=0.054)$, in the second academic study cycle $(47.4 \%$; $95 \%$ CI: $34.7-$ $60.3 \%$; $p=0.001$ ) and having a job in parallel with the study
(7\%; 95\% CI: 2.3-16.1\%; p=0.045) (Figure 3). Contrarily, in the case of students without eating disorders, they were significantly more present in the first cycle $(62.4 \%$; $95 \%$ CI: $54.8-69.9 ; \mathrm{p}=0.011)$ of academic studies than those with eating disorders; also, they were living in a rented residence (36.4\%; 95\% CI: 29.3-43.9\%; $\mathrm{p}=0.003)$ and were underweight persons (19.4\%; 95\% CI: 13.9-26; $\mathrm{p}<0.001)$.
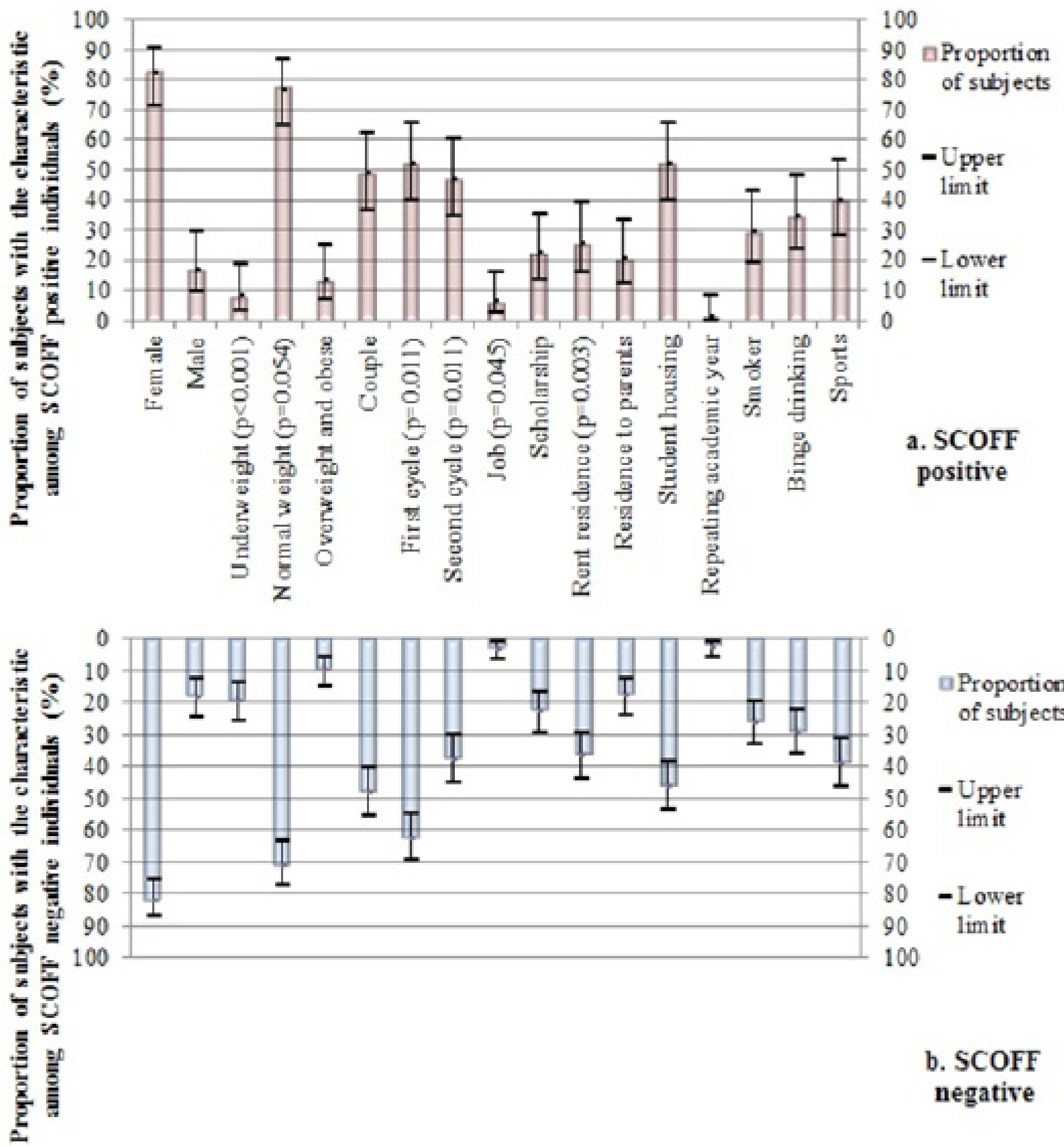

Figure 3. A comparative analysis of the main characteristics as qualitative variables between students screened by SCOFF questionnaire with (a) and without (b) eating disorders. (Legend: upper and lower limit of confidence intervals for each percentage; $p$ - value for the statistical significance test). 
Table II. The factors associated with the students' altered nutritional status ( $\mathrm{N}=222)$.

\begin{tabular}{|c|c|c|c|c|c|c|c|c|c|c|}
\hline \multicolumn{2}{|c|}{ Parameters and groups } & \multirow{2}{*}{\begin{tabular}{|l|} 
Normal \\
$\mathrm{Nr}^{1}$ \\
\end{tabular}} & \multicolumn{4}{|c|}{ Underweight } & \multicolumn{4}{|c|}{ Overweight and obese } \\
\hline & & & $\mathrm{Nr}^{1}$ & $\mathbf{O R}^{2}$ & $95 \% \mathrm{CI}^{3}$ & $\mathbf{p}$ & $\mathrm{Nr}^{1}$ & $\mathbf{O R}^{2}$ & $95 \% \mathrm{CI}^{3}$ & $\mathbf{p}$ \\
\hline \multirow[t]{2}{*}{ Gender } & Female & 134 & 37 & 7.5 & $1-56.7$ & \multirow[t]{2}{*}{0.012} & 11 & 0.2 & $0.07-0.42$ & \multirow[t]{2}{*}{0.001} \\
\hline & Male & 27 & 0 & $0.1^{4}$ & $0.02-1$ & & 13 & 5.9 & $2.37-14.47$ & \\
\hline \multirow[t]{2}{*}{ Marital status } & Un-married & 84 & 19 & 1 & $0.47-1.97$ & \multirow[t]{2}{*}{0.928} & 12 & 0.9 & $0.38-2.16$ & \multirow[t]{2}{*}{0.842} \\
\hline & Couple & 77 & 18 & 1 & $0.5-2.11$ & & 12 & 1.1 & $0.46-2.57$ & \\
\hline \multirow[t]{2}{*}{ Financial difficulties } & Yes & 140 & 30 & 0.7 & $0.25-1.64$ & \multirow[t]{2}{*}{0.355} & 21 & 1.1 & $0.28-3.82$ & \multirow[t]{2}{*}{0.941} \\
\hline & No & 21 & 7 & 1.6 & $0.6-4$ & & 3 & 0.9 & $0.26-3.47$ & \\
\hline \multirow[t]{2}{*}{ Student scholarship } & Yes & 36 & 11 & 1.5 & $0.66-3.25$ & \multirow[t]{2}{*}{0.342} & 3 & 0.5 & $0.14-1.75$ & \multirow[t]{2}{*}{0.269} \\
\hline & No & 125 & 26 & 0.7 & $0.31-1.51$ & & 21 & 2 & $0.56-7.14$ & \\
\hline \multirow[t]{2}{*}{ Study year } & First cycle & 95 & 24 & 1.2 & $0.61-2.7$ & \multirow[t]{2}{*}{0.511} & 14 & 1 & $0.40-2.32$ & \multirow[t]{2}{*}{0.950} \\
\hline & Second cycle & 66 & 13 & 0.8 & $0.37-1.64$ & & 10 & 1 & $0.43-2.45$ & \\
\hline \multirow[t]{3}{*}{ Residency } & Rent & 50 & 15 & 1.5 & $0.52-4.28$ & \multirow{2}{*}{$\begin{array}{l}0.447 \\
0.981 \\
\end{array}$} & 10 & 1.2 & $0.37-3.84$ & 0.758 \\
\hline & Student housing & 81 & 16 & 1 & $0.35-2.75$ & & 9 & 0.7 & $0.21-2.14$ & 0.495 \\
\hline & With parents & 30 & 6 & ref & - & - & 5 & ref & - & - \\
\hline \multirow[t]{2}{*}{ Job } & Yes & 7 & 0 & $0.6^{4}$ & $0.07-4.98$ & \multirow[t]{2}{*}{0.628} & 2 & 2 & $0.39-10.24$ & \multirow[t]{2}{*}{0.397} \\
\hline & No & 154 & 37 & - & - & & 22 & 0.5 & $0.09-2.56$ & \\
\hline \multirow[t]{2}{*}{ Year repetition } & Yes & 2 & 1 & 2.2 & $0.19-25.02$ & \multirow[t]{2}{*}{0.512} & 2 & 7.2 & $1-53.94$ & \multirow[t]{2}{*}{0.025} \\
\hline & No & 159 & 36 & 0.5 & $0.03-5.13$ & & 22 & 0.1 & $0.01-1$ & \\
\hline \multirow[t]{2}{*}{ Smoking } & Yes & 42 & 7 & 0.7 & $0.27-1.61$ & \multirow[t]{2}{*}{0.362} & 11 & 2.4 & $1-5.76$ & \multirow[t]{2}{*}{0.045} \\
\hline & No & 119 & 30 & 1.5 & $0.61-3.7$ & & 13 & 0.4 & $0.17-1$ & \\
\hline Alcohol & Yes & 138 & 28 & 0.5 & $0.21-1.23$ & 0.134 & 21 & 1.2 & $0.32-4.23$ & 0.814 \\
\hline & No & 23 & 9 & 1.9 & $0.8-4.6$ & & 3 & 0.8 & $0.23-3.1$ & \\
\hline Binge drinking & Yes & 51 & 3 & 0.2 & $0.06-0.65$ & 0.003 & 14 & 3 & $1.26-7.25$ & 0.010 \\
\hline & No & 110 & 34 & 5.3 & $1.5-17.9$ & & 10 & 0.3 & $0.13-0.79$ & \\
\hline Sports & Yes & 68 & 7 & 0.3 & $0.13-0.77$ & 0.008 & 12 & 1.3 & $0.57-3.22$ & 0.473 \\
\hline & No & 93 & 30 & 3.1 & $1.3-7.55$ & & 12 & 0.7 & $0.3-1.72$ & \\
\hline
\end{tabular}

${ }^{1} \mathrm{Nr}$ : number of subjects. ${ }^{2} \mathrm{OR}$ : odds ratio. ${ }^{3} 95 \% \mathrm{CI}: 95 \%$ confidence interval. ${ }^{4} \mathrm{OR}$ computed with the unit value.

Table III. A comparative analysis through the basic quantitative parameters of the nutritional status and physical activity, between students screened positive $(\mathrm{N}=57)$ and negative $(\mathrm{N}=165)$ by SCOFF questionnaire $(\mathrm{N}=222)$.

\begin{tabular}{|c|c|c|c|c|c|c|c|}
\hline \multirow[t]{2}{*}{ Parameters } & \multirow[t]{2}{*}{ SCOFF } & \multicolumn{2}{|l|}{ Female } & \multicolumn{2}{|l|}{ Male } & \multicolumn{2}{|c|}{ The entire sample } \\
\hline & & mean $\pm \mathbf{S D}^{1}$ & range & mean \pm SD $^{1}$ & range & mean \pm SD $^{1}$ & range \\
\hline \multirow[t]{2}{*}{ Weight (kg) } & positive & $57.6 \pm 7.42$ & $45-80$ & $81.8 \pm 13.19$ & $57-97$ & $61.8 \pm 12.6$ & $45-97$ \\
\hline & negative & $56.9 \pm 9.3$ & $36-100$ & $77.1 \pm 13.2$ & $60-114$ & $60.5 \pm 12.7$ & $36-114$ \\
\hline \multirow[t]{2}{*}{ Height $(\mathrm{cm})$} & positive & $166.1 \pm 5.5$ & $149-175$ & $180.3 \pm 9$ & $165-193$ & $168.6 \pm 8.2$ & $149-193$ \\
\hline & negative & $165.7 \pm 5.95$ & $150-184$ & $180.8 \pm 7.66$ & $168-197$ & $168.5 \pm 8.6$ & 150-197 \\
\hline \multirow[t]{2}{*}{ BMI $(\mathrm{kg} / \mathrm{m} 2)$} & positive & $20.9 \pm 2.62$ & $17.3-28.7$ & $25.1 \pm 2.82$ & $20.9-28.4$ & $21.6 \pm 3$ & $17.3-28.4$ \\
\hline & negative & $20.7 \pm 3.152$ & $14.2-35.9$ & $23.5 \pm 3.172$ & $20-32$ & $21.2 \pm 3.33$ & $14.2-35.9$ \\
\hline \multirow[t]{2}{*}{ Age (years) } & positive & $21.4 \pm 22$ & $18-28$ & $23.2 \pm 22$ & $20-26$ & $21.7 \pm 2.1$ & $18-28$ \\
\hline & negative & $21.4 \pm 1.78$ & $18-25$ & $22 \pm 2.08$ & $19-27$ & $21.5 \pm 1.84$ & $18-27$ \\
\hline \multirow[t]{2}{*}{ Sports (hours per week) } & positive & $3.7 \pm 1.4$ & $1-7$ & $3.5 \pm 1.7$ & $2-6$ & $3.7 \pm 1.5$ & $1-7$ \\
\hline & negative & $3.9 \pm 1.58$ & $1-8$ & $4.2 \pm 2.47$ & $2-12$ & $4 \pm 1.9$ & $1-12$ \\
\hline \multirow[t]{2}{*}{ Sports (months per year) } & positive & $8.7 \pm 2.7$ & $3-12$ & $12 \pm-$ & 12 & $9.4 \pm 2.7$ & $3-12$ \\
\hline & negative & $9.2 \pm 3.12$ & $2-12$ & $9.4 \pm 3.06$ & $2-12$ & $9.3 \pm 3$ & $2-12$ \\
\hline
\end{tabular}

${ }^{1} \mathrm{SD}$ : standard deviation. ${ }^{2} \mathrm{p}<0,001$ in the comparison of women versus men.

\section{Discussion}

Observing in our study the narrow distribution of men's nutritional status, we also noticed that the overweight and obesity in first degree manifested in almost one-third of male students, far exceeding the prevalence in women. Similar results were observed in the study of Szczuko (2015) in Poland, where the prevalence of overweight and obesity was $24.1 \%$ for male students and $7.8 \%$ for females
[14]. For other Southern European countries, in a literature review for adolescents' dietary habits and nutritional status, made by Cruz (2000), we can observe a prevalence of overweight and obesity around $15-25 \%$ [9]. In the same analysis between genders, the prevalence was higher for female adolescents in the region Lazio, Italy ( $24 \%$ females, $18 \%$ males), Oporto (the reference population), USA (23.2\% females, $16.5 \%$ males), while in Lisbon, Portugal 
(18.4\% males, $15.8 \%$ females) and in the Turin area, Italy ( $24.2 \%$ males, $19.2 \%$ females) the prevalence was higher in male teenagers. In Catalonia, Spain, the prevalence of overweight adolescents was higher for females (14.1\%) than for males $(12.7 \%)$, while obesity prevalence was inversely, higher for males (1.9\%) than for females $(0.1 \%)$ [9]. For the Romanian population, in a study on 7-18 years old school children from the Western region, it was found an overweight prevalence of $18.1 \%$ without significant difference between genders $(16.3 \%$ of girls, $20.7 \%$ for boys), but for obesity (7.2\% total prevalence), the prevalence was significantly higher for boys ( $9 \%)$ than for girls (5.8\%) [15].

The opposing results between counties and regions in the same country regarding the prevalence and patterns of overweight and obesity suggests that the intervention of particular determinants, probably at different points in time, need to be identified and analyzed. Studies showing the nutritional risk factors for cardiovascular diseases in medical students, already conducted in Poland by Ilow et $\mathrm{col}$, found frequently that inappropriate habits such as not having at least three meals/day and not consuming fruits and vegetables daily, were more common in men than women [16]. Another study, conducted also on medical students in Poland, identified bad nutritional habits in correlation with physical activities and nutritional status, with a higher intake of total fat among male than female students [17]. However, more studies are necessary for a better understanding the overweight and obesity phenomenon in this particular population.

The weight excess in youth is particularly worrying. Being recognized as the precursor stage of obesity in adulthood, and in association with others risks factors, it multiplies the probability of cardiovascular diseases, particularly in adolescent males $[5,6,7,18]$. This combination of features increases the risk for the first severe cardiovascular event at a younger age than was known before. In the same sense, as early predictors for cardiovascular diseases, there are very recent results of studies made in Sweden and USA suggesting an association between overweight in adolescence and stroke in adulthood, particularly in men, at least partially through increased blood pressure $[5,19]$. In our Romanian population, the morbidity by cardiovascular diseases in adults under 70 years is higher in men [8], affecting the life expectancy, which is lower than in women. This difference in 2015 was 7.4 years, the female life expectancy being 78.8 years and 71.4 years in males [2]. For our youth population, a better knowledge of the specific characteristics and the particular determinants of the nutritional status are important to decide the necessity of an intervention program and its nature to be effective.

The association of the overweight with male gender, alcohol binge drinking and smoking habits, could suggest the susceptibility of these young people to addictive behaviors. At the same time, overweight was associated with low academic performance, which is a situation that triggers psychological stress. While there are many factors that act simultaneously, it would be interesting to analyze the role played by each of them and to characterize their possible interactions. An explanatory factor was found in the comparative study between medical students in dentistry and those in sport science over five years of academic education, conducted by Kremmler (2016) in Germany. In this study it was established, by measurements of the body composition using the Dual-Energy x-ray-absorptiometry, the elevation of the body mass in the medical group due to increased body fat (total and abdominal) as a consequence of the reduction in their physical activity [20].

The screened eating disorders for a quarter of the students in our sample revealed to be more frequent in the second cycle, in students who also had a job, but without association with an altered nutritional status. This could suggest their occurrence during student lifetime. A similar value of prevalence of eating disorders was found in Germany (14-36\% of adolescents) [21], in Austria (14.6$30.9 \%$ of $10-18$ years old persons) [22], in France (20.5\% of students) [23] and in Spain (21.4\% of adolescents) [24]. So far, it is known that the eating disorders screened by questionnaires rarely become chronic. Only a part would be structured into chronic course, having health consequences as chronic diseases or representing a manifestation of mental disorders $[22,25]$. However, their presence impairs the function of the individual, causes distress and has a negative impact on educational attainment $[21,26]$. As we observed in other studies, the eating disorders detection through the SCOFF questionnaire seemed to be a reliable instrument and easy to use. Its performances had proven to be good, having a sensitivity between $53.7 \%$ and $100 \%$ and specificity between $87.5 \%$ and $93.5 \%$ in different comparative assessments with control groups $[25,27,28]$.

The main limitation of our study was the size of the sample determined by the students' reluctance to complete the questionnaire. This attitude, generally speaking from our practice in public health, represents the lack of practice in real life for filling questionnaires, or represents a consequence of not currently using this method for collecting data in order to investigate different aspects of community health problems. Having developed our study using questionnaire could help to see if it would change this attitude by monitoring students' participation rate in the future evaluations of our annual survey.

Particularly for the participation rate in our survey it was much lower than our expectations for today's student population known as native digital generation, which currently use many electronic devices and systems. We are concerned if the study's responders were significantly different from students who did not respond. This difference is difficult to be established due to the anonymous online participation. 
Another limitation was that the utilization of SCOFF scale non-validated in Romanian language. The SCOFF questionnaire was validated in French, and we could reasonably assert that Romanian is not very different from French, with a common origin, Latin [13]. This potential bias remains certainly low. In addition, eating disorders prevalence in Romania (27\%) was quite similar to that found in France [23].

Also, the students' heterogeneity by their study academic year is mainly due to the manner of selection through the invitation made by the team's academic staff to the students they work with. This procedure of subjects' identification can be the origin of a selection bias. The intervention of this systematic error in our study is less probable because the target population was restricted to medical students, the invitation was made identically by the team members and the link for the online self-administered questionnaire was accessible in the same way for all students. Also the female predominance in our sample of students is in trend with the increasingly number of teenage females who choose medical universities to pursue a medical career in many countries $[29,30]$.

\section{Conclusions}

The nutritional disorders among medical students had different patterns of distribution according to gender. Among female students, a wide range of manifestations of nutritional disorders was present, but mainly toward underweighting. For males, a narrow representation including only overweight and obesity affecting nearly a third of them was shown, which are worrying conditions due to the cardiovascular risk in future young adults. Explanatory factors for these differences remain to be further identified.

The factors associated with overweight and obesity were the male gender, binge drinking, smoking habits and low academic performance.

The eating disorders screened by the questionnaire in a quarter of the students did not affect the nutritional status. These disorders were present especially in students in the second study cycle, having a job in parallel with the medical academic training.

\section{References}

1. Micha R, Peñalvo JL, Cudhea F, Imamura F, Rehm CD, Mozaffarian D. Association between dietary factors and mortality from heart disease, stroke, and type 2 diabetes in the United States. JAMA. 2017;317:912-924.

2. World Health Statistics 2016: Monitoring health for the SDGs, sustainable development goals. Available from: http://www.who. int/gho/publications/world_health_statistics/2016/en/

3. Sidney S, Quesenberry CP Jr, Jaffe MG, Sorel M, NguyenHuynh MN, Kushi LH, et al. Recent trends in cardiovascular mortality in the united states and public health goals. JAMA Cardiol. 2016;1:594-599.

4. Danaei G, Ding EL, Mozaffarian D, Taylor B, Rehm J, Murray
CJ, et al. The preventable causes of death in the United States: comparative risk assessment of dietary, lifestyle, and metabolic risk factors. Plos Medicine. 2009 Apr 28;6(4):e1000058. doi: 10.1371/journal.pmed.1000058.

5. Ohlsson C, Bygdell M, Sondén A, Jern C, Rosengren A, Kindblom JM. BMI increase through puberty and adolescence is associated with risk of adult stroke. Neurology. 2017;89:363-369. 6. Martinovic M, Belojevic G, Evans GW, Kavaric N, Asanin B, Pantovic S, et al. Hypertension and correlates among Montenegrin schoolchildren-a cross-sectional study. Public Health. 2017;147:15-19.

7. Lhachimi SK, Nusselder WJ, Smit HA, Baili P, Bennett K, Fernández E, et al. Potential health gains and health losses in eleven EU countries attainable through feasible prevalences of the life-style related risk factors alcohol, BMI, and smoking: a quantitative health impact assessment. BMC Public Health. 2016 Aug 5;16:734.

8. WHO Noncomunicable Diseases Country Profiles, 2014. Available from: http://www.who.int/nmh/countries/rou en.pdf?ua=1

9. Cruz JA. Dietary habits and nutritional status in adolescents over Europe--Southern Europe. Eur J Clin Nutr. 2000;54 Suppl 1:S29-S35.

10. Firth J. Levels and sources of stress in medical students. $\mathrm{Br}$ Med J (Clin Res Ed). 1986;292(6529): 1177-1180.

11. Compton MT, Carrera J, Frank E. Stress and depressive symptoms/dysphoria among US medical students: results from a large, nationally representative survey. J Nerv Ment Dis. 2008;196:891-897.

12. Dahlin M, Joneborg N, Runeson B. Stress and depression among medical students: a cross-sectional study. Med Educ. 2005;39:594-604.

13. Garcia FD, Grigioni S, Allais E, Houy-Durand E, Thibaut F, Déchelotte P. Detection of eating disorders in patients: validity and reliability of the French version of the SCOFF questionnaire. Clin Nutr. 2011;30(2):178-181.

14. Szczuko M, Gutowska I, Seidler T. Nutrition and nourishment status of Polish students in comparison with students from other countries. Rocz Panstw Zakl Hig. 2015;66(3):261-268.

15. Emandi AC, Puiu M, Gafencu M, Pienar C. Overweight and obesity in school age children in western Romania. Rev Med Chir Soc Med Nat Iasi. 2013;117(1):36-45.

16. Ilow RA, Regulska-Ilow B, Różańska D. Dietary habits of Wroclaw Medical University students (Poland). Rocz Panstw Zakl Hig. 2017;68(1):23-32.

17. Grygiel-Górniak B, Tomczak A, Krulikowska N, Przyslawski J, Seraszek-Jaros A, Kaczmarek E. Physical activity, nutritional status, and dietary habits of students of a medical university. Sport Sci Health. 2016;12:261-267.

18. Cuzzolaro M. Eating disorders and obesity. In: Sbraccia P, Clinical Management of Overweight and Obesity: Recommendations of the Italian Society of Obesity (SIO). Springer International Publishing Switzerland; 2016, pp 103-123. 19. Rexrode KM, Kimm SYS. Adolescent weight gain confers long-term increased stroke risk: Weighty matters. Neurology. 2017;89(4):312-313.

20. Kemmler W, von Stengel S, Kohl M, Bauer J. Impact of exercise changes on body composition during the college years--a five year randomized controlled study. BMC Public Health. 2016 Jan 19;16:50.

21. Nagl M, Jacobi C, Paul M, Beesdo-Baum K, Höfler M, Lieb $\mathrm{R}$, et al. Prevalence, incidence, and natural course of anorexia and 
bulimia nervosa among adolescents and young adults. Eur Child Adolesc Psychiatry. 2016;25:903-918.

22. Philipp J, Zeiler M, Wagner G, Waldherr K, Nitsch M, Dur W, Karwautz A. Disordered eating behaviours and related risk and protective factors: First epidemiological survey in Austria. Eur Child Adolesc Psychiatry. 2015;24:1 Suppl 1:S80.

23. Tavolacci MP, Grigioni S, Richard L, Meyrignac G, Déchelotte P, Ladner J. Eating Disorders and Associated Health Risks Among University Students. J Nutr Educ Behav. 2015;47(5):412-420.

24. Estecha Querol S, Fernández Alvira JM, Mesana Graffe MI, Nova Rebato E, Marcos Sánchez A, Moreno Aznar LA. Nutrient intake in Spanish adolescents SCOFF high-scorers: the AVENA study. Eat Weight Disord. 2016;21(4):589-596.

25. Buchholz LJ, King PR, Wray LO. Identification and Management of Eating Disorders in Integrated Primary Care: Recommendations for Psychologists in Integrated Care Settings.
J Clin Psychol Med Settings. 2017;24:163-177.

26. Hansson E, Daukantaite D, Johnsson P. Typical patterns of disordered eating among Swedish adolescents: associations with emotion dysregulation, depression, and self-esteem. J Eat Disord. 2016 Nov 4;4:28.

27. Morgan JF, Reid F, Lacey JH. The SCOFF questionnaire: a new screening tool for eating disorders. West J Med. 2000;172(3):164165.

28. Solmi F, Hatch S, Hotopf M, Treasure J, Micali N. Validation of the SCOFF questionnaire for eating disorders in a multiethnic general population sample. Int J Eat Disord. 2015;48:312-316. 29. Phillips SP, Austin EB. The feminization of medicine and population health. JAMA. 2009;301(8):863-864.

30. Lefevre JH, Roupret M, Kerneis S, Karila L. Career choices of medical students: a national survey of 1780 students. Med Educ. 2010;44:603-612. 